\title{
Nanodiamond dispersions in nanostructured metals
}

\author{
D. Nunes $* * * * * * *$ J. B. Correia**, P. A. Carvalho******** \\ * Associação Euratom/IST, Instituto de Plasmas e Fusão Nuclear - Laboratório Associado, Instituto \\ Superior Técnico, Av. Rovisco Pais, 1049-001 Lisboa, Portugal \\ ** ICEMS, Instituto de Ciência e Engenharia de Materiais e Superfícies, Instituto Superior Técnico, \\ Av. Rovisco Pais, 1049-001 Lisboa, Portugal \\ *** LNEG, Laboratório Nacional de Energia e Geologia, Estrada do Paço do Lumiar, 1649-038 \\ Lisboa, Portugal \\ **** Departamento de Bioengenharia, Instituto Superior Técnico, Universidade Técnica de Lisboa, \\ Av. Rovisco Pais, 1049-001 Lisboa, Portugal
}

A microstructure refined to the nanometer scale originates mechanical property improvements [1]. However ultra-fine grain metals present low thermal stability [1,2], requiring the presence of particle dispersions to delay coarsening by grain boundary pinning. Nanoscale dispersions of diamond or graphite offer therefore thermal stability potential, combined with high hardness [1-6] and thermal conductivity for diamond [1], and self-lubricating properties in the case of graphite [6]. Copperdiamond $(\mathrm{Cu}-\mathrm{nD})$ and copper-graphite $(\mathrm{Cu}-\mathrm{G})$, nickel-diamond (Ni-nD) and nickel-graphite (Ni-G), as well as tungsten-diamond (W-nD) and tungsten-graphite (W-G) nanostructured composites have been produced by mechanical synthesis and subsequent heat-treatments. Fundamental challenges involve bonding carbon phases to the chosen matrices: copper exhibits an intrinsically difficult bonding with carbon; while tungsten is a strong carbide former; with Ni exhibiting intermediate characteristics. In addition, carbon phases are prone to amorphization by high-energy milling. Transmission electron microscopy (TEM) observations showed homogeneous particle distributions and intimate bonding between the metallic matrix and the carbon phases. Ring diffraction patterns of the chemically extracted carbon phases demonstrated that nanodiamond milled with $\mathrm{Cu}$ preserved crystallinity (Figure 1), while an essentially amorphous nature could be inferred for graphite. Systematic variation of the processing parameters enabled to minimize carbide formation with $\mathrm{Ni}$ and $\mathrm{W}$ matrices. Heattreatment of the nanostructured of Ni-nD composites induced the transformation of nanodiamond into onion-like carbons (OLC) inside the Ni nanostructured matrix (Figure 2). Hardening mechanisms and the load transfer ability to the reinforcement particles, as well as thermal stability, have been evaluated through microhardness tests.

\section{References}

1. Srivatsan T.S. et al., Mater. Design 23: 29, 2002

2. Decker B.F. and Harker, D., Trans. AIME 188: 887, 1950

3. Thuvander M. et al., Mater. Sci. Tech., 17: 961, 2001

4. Livramento V. et al., Diamond Relat. Mater. 16: 202, 2007

5. Nunes D. et al., Mater. Sci. Eng. A 528: 8610-8620, 2011

6. Nunes D. et al., Fusion Eng. Design 86: 2589-2592, 2011

7. Nunes D. et al., Mater. Sci. Forum 636: 682, 2010

8. Hanada K. et al., Diamond Relat. Mater. 16: 2054-2057, 2007

9. Livramento V. et al., Diamond Relat. Mater. 16: 202, 2007

10. Yoshida K. and Morigami H., Microelect. Reliab. 44: 303, 2004

11. Nickchi T. et al., Mater. Design 32: 3548, 2011 

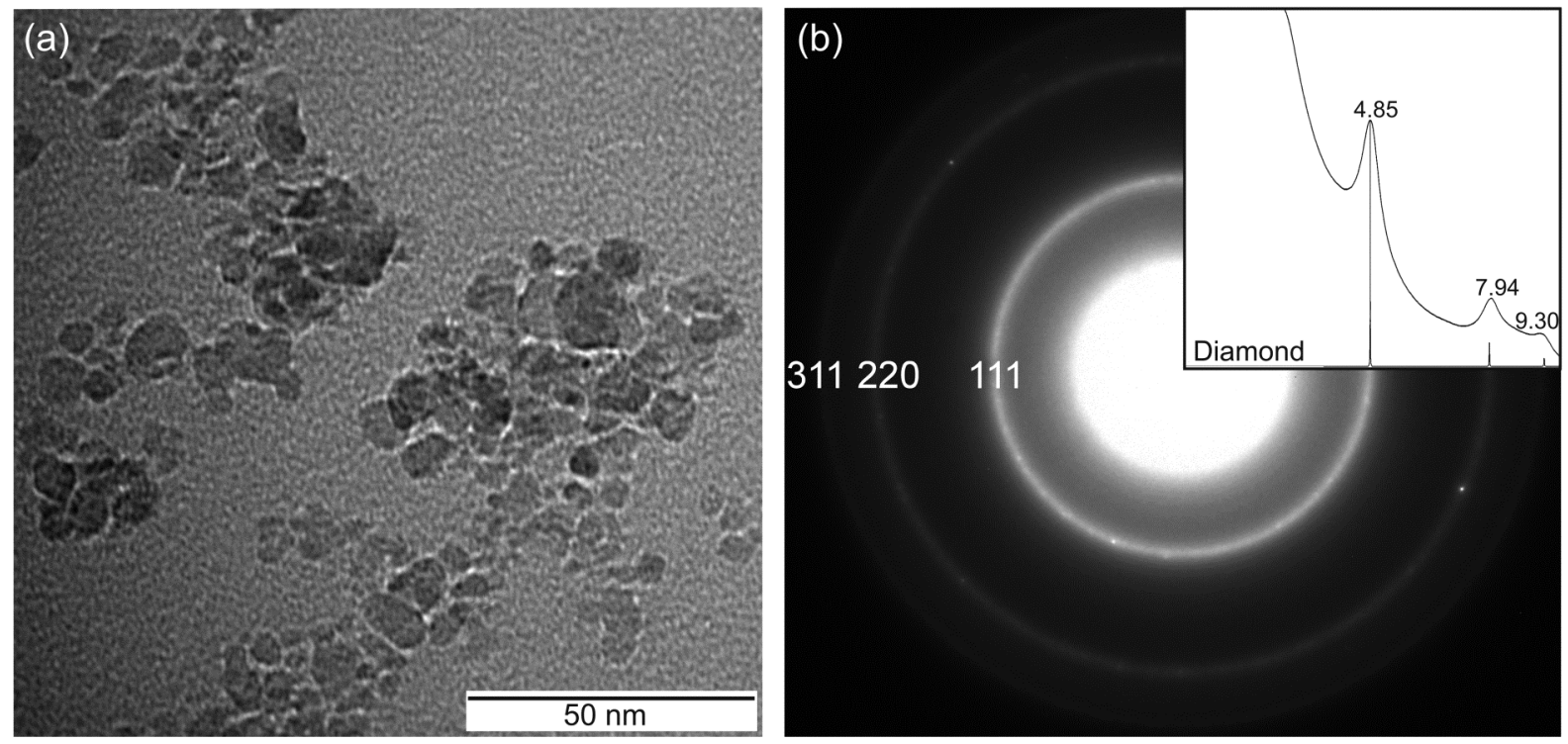

Figure 1. (a) Bright-field TEM image of the $\mathrm{nD}$ chemically extracted from $\mathrm{Cu}-\mathrm{nD}$ composites (b) Ring diffraction pattern with integrated radial profile (diamond simulation included with legend in $\mathrm{nm}^{-1}$ ).
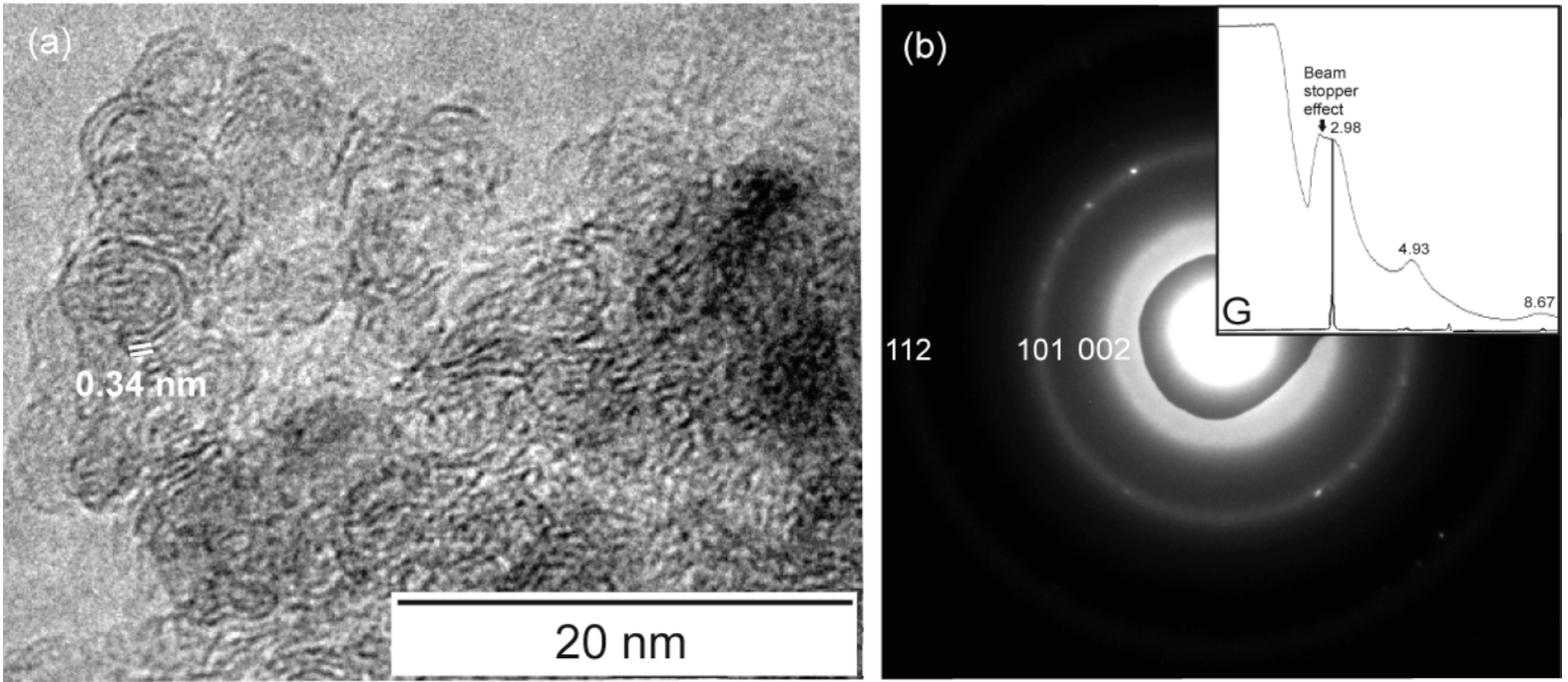

Figure 2. (a) Bright-field TEM image of the material chemically extracted from heat-teatred Ni-nD composites heat-treated at $1673 \mathrm{~K}$. (b) Ring diffraction pattern with integrated radial profile (graphite simulation included with legend in $\mathrm{nm}^{-1}$ ).

Financial support received from the Portuguese Science and Technology foundation under the contract PTDC/CTM/100163/2008 grant. 